\title{
Continuous Intra-Articular Ropivacaine/Tramadol Combination Infusion Therapy Improves Postoperative Outcome of Total Knee Arthroplasty
}

\author{
Ayman Mohamady Eldemrdash*, El-Sayed Mohamed Abdelzaam \\ Department of Anesthesiology, Faculty of Medicine, Aswan and Benha University, Egypt \\ Email: *aymaneldemrdash@yahoo.com, Sayedzim12@yahoo.com
}

How to cite this paper: Eldemrdash, A.M. and Abdelzaam, E.-S.M. (2018) Continuous Intra-Articular Ropivacaine/Tramadol Combination Infusion Therapy Improves Postoperative Outcome of Total Knee Arthroplasty. Open Journal of Anesthesiology, 8, 137-146.

https://doi.org/10.4236/ojanes.2018.85015

Received: March 23, 2018

Accepted: May 20, 2018

Published: May 23, 2018

Copyright $\odot 2018$ by authors and Scientific Research Publishing Inc. This work is licensed under the Creative Commons Attribution International License (CC BY 4.0).

http://creativecommons.org/licenses/by/4.0/

(c) (i) Open Access

\begin{abstract}
Objectives: To evaluate the postoperative analgesic yield of continuous intra-articular (IA) ropivacaine/tramadol infusion as against infusion of ropivacaine alone after total knee arthroplasty. Patients and Methods. Sixty patients accompanied by arthrosis were randomly divided into three equal groups: The ropivacaine group, which obtained a continuous intraarticular (IA) infusion of ropivacaine alone; the combination group, which obtained a continuous (IA) infusion of a combination of ropivacaine and tramadol at a rate of $6 \mathrm{ml} / \mathrm{h}$ for $72 \mathrm{~h}$ postoperatively; and the control group, which did not receive IA medications. After release of the ischemic tourniquet and assurance of haemostasis, a vacuum drainage tube was applied. The (IA) infusion was delivered through a multipored catheter for $72 \mathrm{~h}$. Postoperative pain was assessed using visual analogue pain scale (VAS), and intravenous meperidine was administered as rescue analgesia if the (VAS) pain score was greater than or equal to (4) or on patient's request. The total rescue analgesia consumption, angle of flexion of the knee and hospital stay were recorded. Results: The ability to achieve better angle of flexion was significantly higher in the combination group compared with the other groups, with a significant difference in favour of the ropivacaine group compared with the control group. At $2 \mathrm{~h}$ postoperatively, the mean pain (VAS) scores were significantly lower in patients who received (IA) analgesia compared with the control group and in the ropivacaine/tramadol group versus the ropivacaine group. The number of requests and total dose of rescue analgesia consumed were significantly lower with (IA) analgesia, with a significant difference in favour of the combination group. There was significant correlation between pain (VAS) scores and angle
\end{abstract}


of flexion of the knee joint. Conclusion: Continuous (IA) ropivacaine/tramadol infusion safely reduced postoperative pain and spared administration of rescue analgesics with a significantly improved range of joint movement.

\section{Keywords}

Continuous, Infusion, Intra-Articular, Total Knee Arthroplasty, Tramadol, Ropivacaine

\section{Introduction}

Arthroplasty surgeries carry multiple concerns for both surgeons and anaesthetists. First, patients who need arthroplasty surgeries are usually geriatric patients who are handicapped or immobilized or who have been suffering from slow painful motion since years. Second, these patients mostly have additional morbidities, which may delay their postoperative recovery [1].

An aspect of prime importance is the immediate postoperative pain, which imposes both physical and mental burden, preventing patients from trying to move their joints and hence prolonging the duration of postoperative care and delaying rehabilitation [2].

Multiple analgesic modalities were proposed for management of postoperative pain in patients undergoing arthroplastic surgery. Remeand et al. [3] reported that intravenous ketamine had a morphine-sparing effect after total hip arthroplasty, facilitated rehabilitation at 1 month, and decreased postoperative chronic pain up to 6 months after surgery. Sundarathiti et al. [4] documented that continuous femoral nerve block represents the optimal analgesia with fewer side effects and greater patient satisfaction. Andersen et al. [5] noticed that analgesia with ropivacaine infiltration for the entire wound in bilateral total knee arthroplasty to be effective in early postoperative pain management. Other studies tried the use of various intra-articular medications for pain management after arthroplastic surgeries.

Fu et al. [6] reported that an intra-articular cocktail analgesic injection composed of bupivacaine, morphine, and betamethasone reduced the need for morphine and offered better pain control without apparent risks following total knee arthroplasty. Garcia et al. [7] noticed that postoperative intra-articular application of morphine advocated a longer period without deliver analgesics and decreased their consumption in the first $24 \mathrm{~h}$ as compared with placebo. The current prospective comparative study aimed to evaluate the postoperative analgesic yield of intra-articular continuous ropivacaine/tramadol infusion against infusion of ropivacaine alone after total knee arthroplasty.

\section{Patients and Methods}

The current controlled prospective comparative study was conducted at De- 
partments of Anaesthesia and surgical I.C.U in Aswan and Benha University Hospital, between Sep. 2014 and May 2016. After approval of the study protocol by the Local Ethical Committee and obtaining written fully informed consent from the patient or a near relative of the patient. Sixty patients were included in this prospective, randomized, double-blind, age $65-80 \mathrm{yr}$, ASA physical status I-II, with primary knee arthrosis and assigned for total knee arthroplasty were enrolled in the study. Exclusion criteria were patients with chronic pain or taking chronic opioid medication, known allergy to the medications used, contraindications to performing regional anaesthesia and patients with neurological or psychological diseases that may interfere with assessment, those contraindication for the study drugs, and those with orthopaedic diseases other than knee arthrosis were excluded from the study.

Using sealed envelopes, patients were randomly divided into three equal groups $(\mathrm{n}=20)$ : the ropivacaine group (group $\mathrm{R})$, which included patients who received continuous intra-articular infusion of ropivacaine alone; the combination group (group RT), which included patients who received continuous intra-articular infusion of a combination of ropivacaine and tramadol; and the control group (group C), which included patients who did not receive intra-articular medications and were maintained on rescue analgesia.

All surgeries were conducted under spinal anaesthesia. All patients had undergone implantation with the cemented Nex-Gen1 LPS with a patellar component (Zimmer Inc., Warsaw, Indiana, USA). After release of the ischemic tourniquet and assurance of haemostasis, a vacuum drainage tube was applied. Thereafter, a multipore catheter was inserted to ensure equal distribution of infusion fluid throughout the joint cavity.

After airtight wound closure, the vacuum drainage system was activated until complete drainage of the joint cavity was achieved, following which the system was inactivated and analgesic infusion was commenced. Dose calculation and preparation of infusions: in the ropivacaine group, $5 \mathrm{ml}$ of ropivacaine (7.5 $\mathrm{mg} / \mathrm{ml}$ ) was diluted with $5 \mathrm{ml}$ saline to achieve a concentration of $3.75 \mathrm{mg} / \mathrm{ml}$, and $5 \mathrm{ml}$ of this diluted ropivacaine $(18.75 \mathrm{mg})$ solution was infused for $45 \mathrm{~min}$ by means of a syringe pump during locking of the vacuum system, which was activated for $15 \mathrm{~min}$ to withdraw the infused fluid, and blood if present, out of the joint cavity; the procedure was repeated hourly for $72 \mathrm{~h}$. In the combination group each tramadol ampoule containing $100 \mathrm{mg} / 2 \mathrm{ml}$ was diluted with normal saline to $20 \mathrm{ml}$ so that each $\mathrm{ml}$ contained $5 \mathrm{mg}$ of tramadol. The infusion fluid was prepared from $5 \mathrm{ml}$ of diluted ropivacaine $(18.75 \mathrm{mg})$ and $1 \mathrm{ml}$ of diluted tramadol $(5 \mathrm{mg})$; this $6 \mathrm{ml}$ solution was infused for 45 min by means of a syringe pump during locking of the vacuum system as in the ropivacaine group.

The analgesic infusion was commenced in the same order for the third postoperative day. Postoperative pain was assessed using a 10-point visual analogue pain scale (VAS) with 0 indicating no pain and 10 indicating the worst intolerable pain. Rescue analgesia in the form of intravenous meperidine was given if the 
VAS pain score was greater than or equal to 4 or on patient's request. The daily consumption of rescue analgesia was determined. The frequency of side effects such as nausea, vomiting, constipation, and catheter site infection was recorded. The range of joint motion achieved daily was assessed as the angle of knee flexion-that is, the angle formed by the leg and the thigh. The length of hospital stay was also recorded.

\section{Statistical Analysis}

The obtained data were presented as mean \pm SD and ranges. Results were analysed using the Wilcoxon ranked test for unrelated data (Z-test) and the w2-test. Possible correlations were evaluated using Pearson's correlation coefficient ( $r$ ). Statistical analysis was carried out using the SPSS for Windows statistical package (Version 15, 2006; SPSS Inc., Chicago, Illinois, USA). A P-value less than 0.05 were considered statistically significant.

\section{Results}

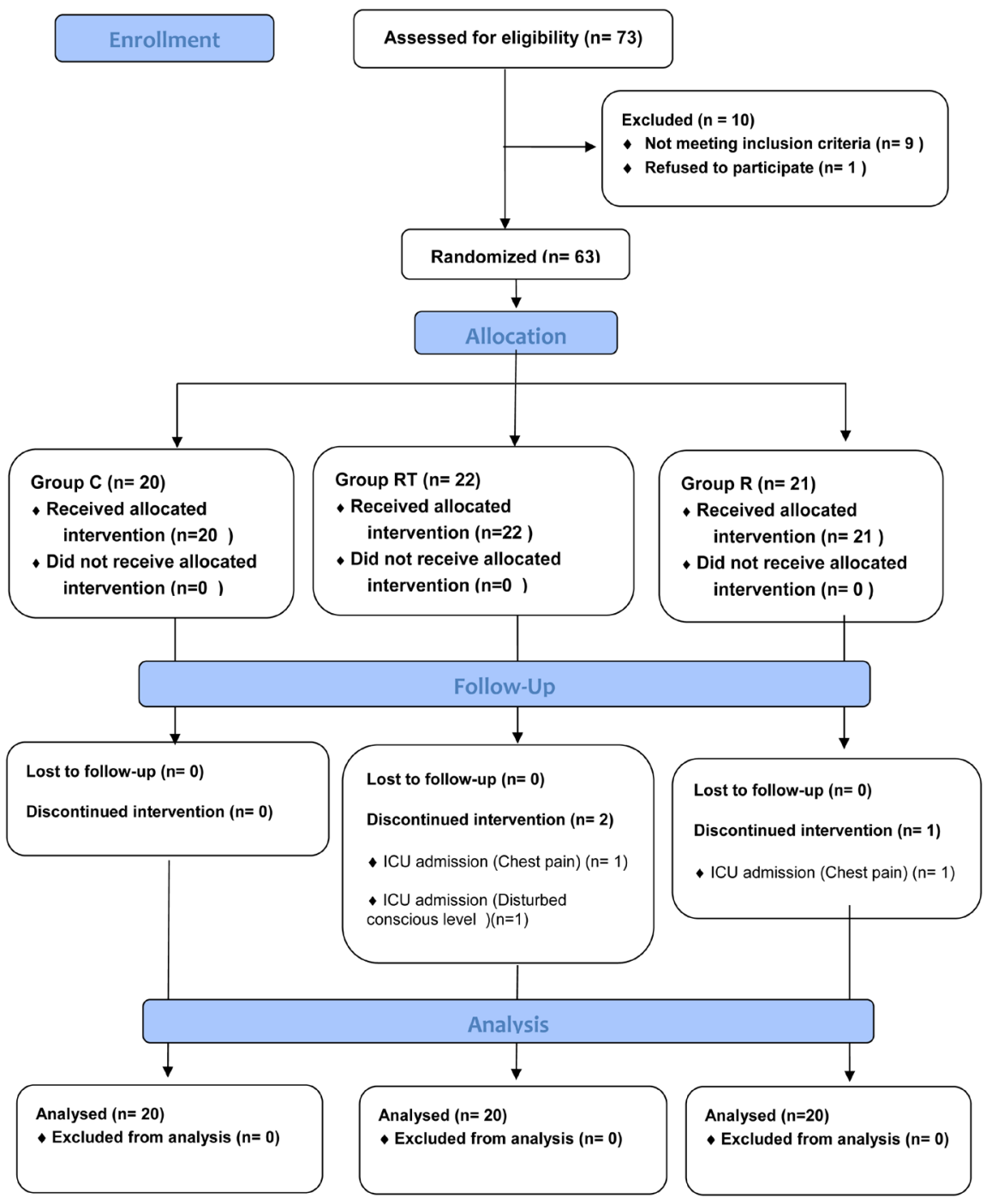


Sixty patients completed the study, 33 had left and 27 had right arthrosis. There was no significant difference between studied groups as regards demographic data and duration of symptoms ( $\mathrm{p}>0.05$ ) (Table 1 ).

As regards duration of surgery, amount of daily drainage (Figure 1) and hospital stay there was no significant difference between studied groups (Table 2).

All patients showed a progressive increase in the range of motion throughout the first three postoperative days. However, the angle of knee joint movement was significantly $(\mathrm{P}<0.05)$ better in the combination group compared with the other groups, with a significantly wider scale of motion in the ropivacaine group compared with the control group (Table 2) (Figure 2).

At time zero ( $2 \mathrm{~h}$ postoperatively) for first evaluation of the pain VAS score, the mean pain VAS score was significantly lower in patients who received intrarticular analgesia compared with the control group, with significantly lower scores in favour of the combination group.

At $2 \mathrm{~h}, 35$ patients requested for rescue analgesia: 16 in the ropivacaine group, 20 in the control group and 9 in the combination group with significantly lower frequency in the combination group compared with both the other groups, with non-significant $(\mathrm{P}>0.05)$ difference in favour of the ropivacaine group.

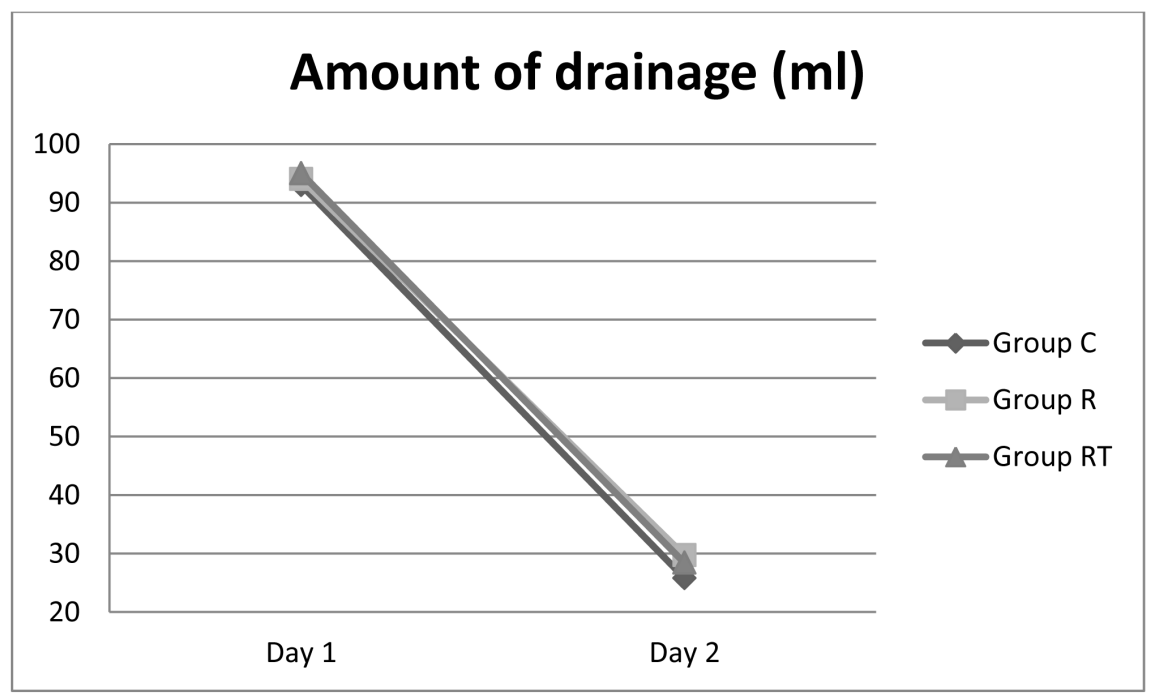

Figure 1. Amount of drainage (ml).

Table 1. Patients' demographic data and duration of symptoms.

\begin{tabular}{cccc}
\hline & Control group & Ropivacaine group & Combination group \\
\hline Age (years) & $73.5 \pm 8.9$ & $73.3 \pm 9.2$ & $74.5 \pm 8.4$ \\
Gender (M:F) & $7: 13$ & $6: 14$ & $8: 12$ \\
Weight (Kg) & $85.9 \pm 3.6$ & $86.3 \pm 4.7$ & $87.2 \pm 3.7$ \\
Height (cm) & $167 \pm 4.8$ & $167.4 \pm 4.7$ & $166.8 \pm 4.8$ \\
Duration of symptom (years) & $12.6 \pm 3.7$ & $13.7 \pm 3.5$ & $12.8 \pm 3.8$ \\
\hline
\end{tabular}

Data are presented as mean $\pm \mathrm{SD}$. Gender presented as numbers. 


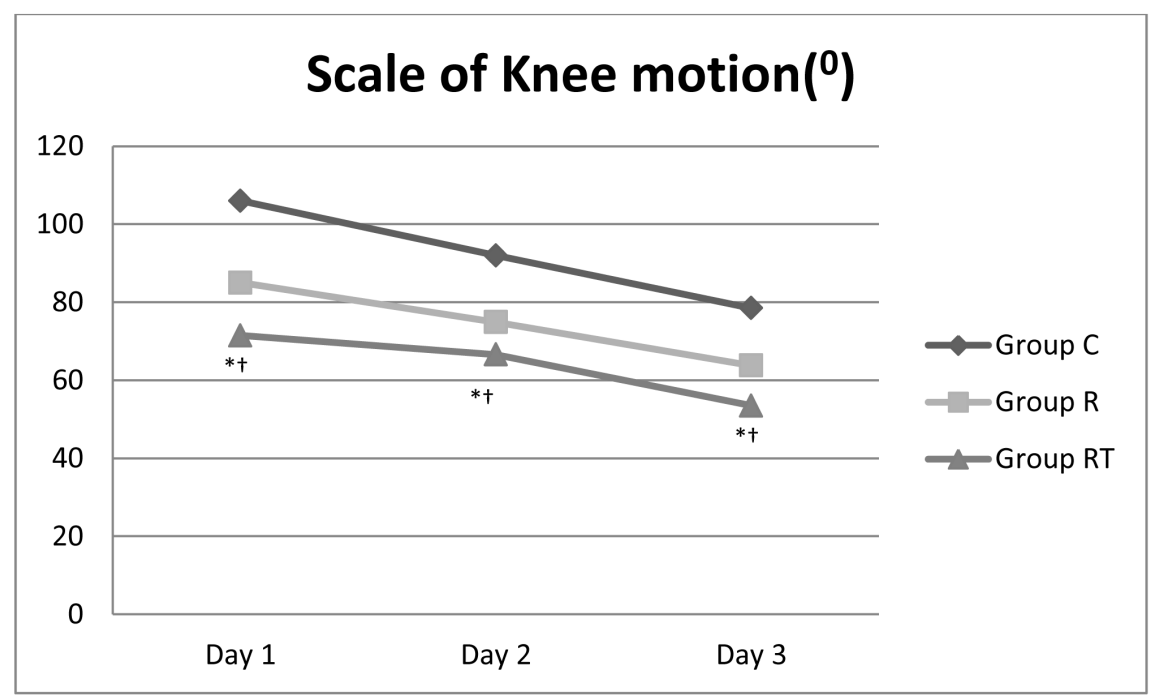

Figure 2. Scale of Knee motion.

Table 2. Patients' operative and postoperative data.

\begin{tabular}{ccccc}
\hline & Control group & Ropivacaine group & Combination group \\
\hline \multicolumn{2}{c}{ Duration of surgery (min) } & $67 \pm 11.3$ & $67.8 \pm 12.4$ & $68.3 \pm 12.5$ \\
\hline & Day 1 & $106 \pm 14.9$ & $85 \pm 14.6^{*}$ & $71.5 \pm 14.2^{* \dagger}$ \\
Scale of motion ( $\left.{ }^{\circ}\right)$ & Day 2 & $92 \pm 14.8$ & $74.9 \pm 14.7^{*}$ & $66.6 \pm 12.8^{* \dagger}$ \\
& Day 3 & $78.5 \pm 12.2$ & $63.8 \pm 11.9^{*}$ & $53.5 \pm 12.5^{* \dagger}$ \\
$\begin{array}{c}\text { Amount of drainage } \\
(\text { ml) }\end{array}$ & Day 1 & $93 \pm 25.6$ & $94 \pm 33.5$ & $95 \pm 29.1$ \\
Hospital stay (days) & Day 2 & $25.8 \pm 11.6$ & $29.7 \pm 8.1$ & $28.4 \pm 10.8$ \\
\hline
\end{tabular}

Data are presented as mean \pm SD. ${ }^{\star}$ Significant vs. the control group. ${ }^{\dagger}$ Significant vs. the ropivacaine group.

Thereafter, all studied patients showed progressive decline in pain VAS scores with significantly lower scores in the study groups compared with the control group and a non-significant difference in favour of the combination group until $12 \mathrm{~h}$ postoperatively.

At 24,48 , and $72 \mathrm{~h}$, pain VAS scores were significantly lower in the study groups compared with the control group, with significant difference in favour of the combination group (Table 3) (Figure 3).

The number of requests for rescue analgesia and total dose of meperidine consumed up to $72 \mathrm{~h}$ postoperatively were significantly $(\mathrm{P}<0.05)$ lower in patients who received intra-articular analgesia compared with the control group, with significantly fewer requests and lower total meperidine dose in the combination group compared with the ropivacaine group (Table 3).

There was a significant positive correlation $(r=0.376, P=0.017)$ between pain VAS scores and angle of knee joint flexion recorded at $72 \mathrm{~h}$ postoperatively in the intra-articular groups. No catheter port-site infection was reported, and no complications related to the procedure or medications were reported. There 


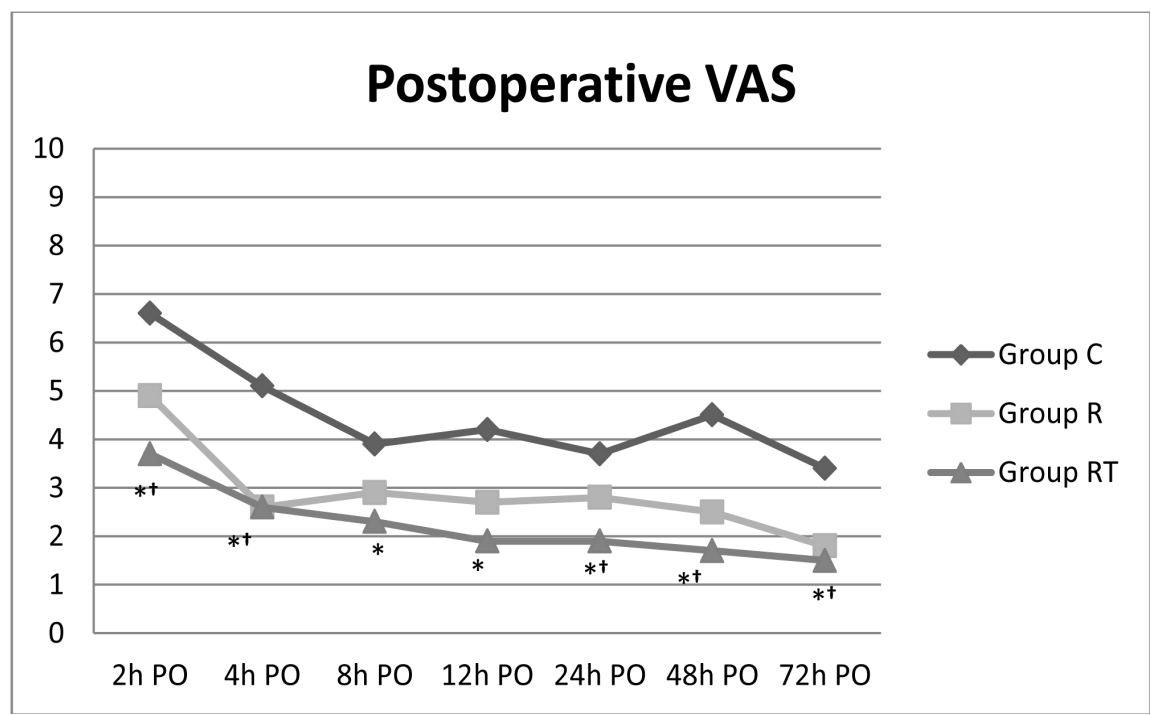

Figure 3. Postoperative VAS.

Table 3. Patients' pain data.

\begin{tabular}{|c|c|c|c|c|}
\hline & & Control group & Ropivacaine group & Combination group \\
\hline & $2 \mathrm{~h} \mathrm{PO}$ & $6.6 \pm 1.4$ & $4.86 \pm 1^{*}$ & $3.7 \pm 0.8^{* \dagger}$ \\
\hline & $4 \mathrm{~h} \mathrm{PO}$ & $5.1 \pm 1.3$ & $2.65 \pm 1.3^{*}$ & $2.55 \pm 1.5^{*}$ \\
\hline & $8 \mathrm{~h} \mathrm{PO}$ & $3.9 \pm 2.2$ & $2.9 \pm 1.2^{\star}$ & $2.3 \pm 0.8^{\star}$ \\
\hline \multirow[t]{4}{*}{ VAS } & $12 \mathrm{~h}$ PO & $4.2 \pm 1.4$ & $2.66 \pm 1.3^{*}$ & $1.9 \pm 1.2^{*}$ \\
\hline & $24 \mathrm{~h}$ PO & $3.7 \pm 1.6$ & $2.8 \pm 1.3^{*}$ & $1.91 \pm 1.2^{* \dagger}$ \\
\hline & $48 \mathrm{~h}$ PO & $4.5 \pm 1.6$ & $2.5 \pm 1.2^{\star}$ & $1.66 \pm 0.8^{* \dagger}$ \\
\hline & 72 h PO & $3.4 \pm 1.5$ & $1.8 \pm 1.1^{*}$ & $1.5 \pm 0.6^{* \dagger}$ \\
\hline \multicolumn{2}{|c|}{$\begin{array}{l}\text { Number of request of } \\
\text { rescue analgesia (time) }\end{array}$} & $5.4 \pm 1.18$ & $3.5 \pm 0.9^{*}$ & $1.88 \pm 0.57^{* \dagger}$ \\
\hline \multicolumn{2}{|c|}{ Total dose of meperidine } & $268 \pm 59$ & $172 \pm 31^{\star}$ & $91.9 \pm 32.6^{* \dagger}$ \\
\hline
\end{tabular}

Data are presented as mean \pm SD. PO, postoperative; VAS, visual analogue pain scale. ${ }^{\star}$ Significant vs. the control group. ${ }^{\dagger}$ Significant vs. the ropivacaine group.

were no cases of drug-related allergy or side effects, nor were there port-site infection or complications.

\section{Discussion}

Intra-articular analgesia proved effective for management of postoperative pain in total knee arthroplasty patients, irrespective of the medication used, as manifested by the significantly lower pain VAS scores recorded throughout $72 \mathrm{~h}$ after surgery, in comparison with patients who did not receive intra-articular analgesia (group C). In support of the benefits of intra-articular analgesia, patients who received intra-articular analgesia showed a significantly wider scale of joint motion compared with the (group C), with significantly wider scale of motion recorded in the (group RT) compared with the (group R) alone. 
Commensurate with these results, Dobrydnjov et al. [8] found that continuous intra-articular ropivacaine infusion reduced the incidence of high pain intensity during first exercises compared with ropivacaine extra-articular infusion and could therefore be expected to improve mobilization up to $24 \mathrm{~h}$ after total knee arthroplasty.

However, the results obtained from continuous ropivacaine infusion were superior to those reported by Chen et al. [9] who found that continuous intra-articular infusion of $0.5 \%$ bupivacaine at $2 \mathrm{ml} / \mathrm{h}$ does not provide sustained postoperative pain relief in patients undergoing THA. This difference could be attributed to the use of a catheter with multiple pores and the larger volume used, allowed homogenous distribution of the fluid throughout the joint cavity and provided better pain relief.

The provided postoperative pain control measure allowed rapid movement in patients, with a progressively increasing range of motion, thus inducing alleviation of patient apprehension and release of emotional stress with a subsequent uneventful postoperative course and easy rehabilitation.

In line with data, Koltka et al. [10] tried intra-articular injection of magnesium sulfate, levobupivacaine, or lornoxicam compared with placebo and found that administration of all the drugs provided better analgesia compared with placebo and allowed early rehabilitation after knee arthroscopic surgery.

Commensurate with the use of combined intra-articular therapy, Senthilkumaran et al. [11] and Eroglu et al. [12] reported that simple addition of morphine to the intra-articular injection of levobupivacaine gives a significant reduction in opiate analgesic requirement after anterior cruciate ligament reconstruction.

Ayoglu et al. [13] and, Cekic et al. [14] also found intra-articular administration of a combination of tramadol and ketamine to be more effective in decreasing postoperative daily analgesic consumption compared with administration alone or with a local anaesthetic.

These beneficial effects of intra-articular analgesia could be attributed to the direct target effect of the analgesic used; however, considering the fact that ropivacaine is a fixed medication provided for both groups, the enhanced analgesic effect of the combination of ropivacaine and tramadol could be attributed to the effect of tramadol. Moreover, considering the weak absorption occurring through the tissues of the joint cavity, the effect of tramadol could not be attributed to a systemic effect but mostly to a local effect.

Such data were dependent on the previous work of Gutierez et al. [15], who found that adding intra-articular fentanyl to the combination of epinephrine plus bupivacaine did not decrease pain, nor did it increase the analgesia time or the range of motion in patients undergoing knee arthroscopy.

As an explanation for the varied effects of opiates, Liu and Wang [16] found the A118G polymorphism of the mu-opioid receptor gene resulting in the substitution of an amino acid to be associated with functional effects and response to 
opioid treatment.

The obtained results and review of the literature allowed us to conclude that continuous intra-articular tramadol/ropivacaine infusion safely reduced postoperative pain scores and spared rescue analgesics with a significantly improved range of joint movement. The shortage in this study in a form of short period of follow up 3 days only (should be followed up for a long period). In the future studies we recommended that the follow up as regard the range of motion, Postoperative VAS score and other parameter must be more than 3 days and if a long time treatment will have a complications or not.

\section{References}

[1] Imasogie, N.N., Singh, S., Watson, J.T., Hurley, D. and Morley-Forster, P. (2009) Ultra Low-Dose Naloxone and Tramadol/Acetaminophen in Elderly Patients Undergoing Joint Replacement Surgery: A Pilot Study. Pain Research and Management, 14, 103-108. https://doi.org/10.1155/2009/497217

[2] Eren, M., Koltka, K., Köknel Talu, G., Așik, M. and Ozyaln, S. (2008) Comparison of Analgesic Activity of Intraarticular Lornoxicam, Bupivacaine and Saline after Knee Arthroscopy. Agri, 20, 17-22.

[3] Remeand, F., Le Tendre, C., Baud, A., Couvret, C., Pourrat, X., Favard, L., et al. (2009) The Early and Delayed Analgesic Effects of Ketamine after Total Hip Arthroplasty: A Prospective, Randomized, Controlled, Double-Blind Study. Anesthesia \& Analgesia, 109, 1963-1971. https://doi.org/10.1213/ANE.0b013e3181bdc8a0

[4] Sundarathiti, P., Ruananukul, N., Channum, T., Kitkunasathean, C., Mantay, A., Thammasakulsiri, J. and Sodsee, W. (2009) A Comparison of Continuous Femoral Nerve Block (CFNB) and Continuous Epidural Infusion (CEI) in Postoperative Analgesia and Knee Rehabilitation after Total Knee Arthroplasty (TKA). Journal of the Medical Association of Thailand, 92, 328-334.

[5] Andersen, L.Ø., Husted, H., Kristensen, B.B., Otte, K.S., Gaarn-Larsen, L. and Kehlet, H. (2010) Analgesic Efficacy of Subcutaneous Local Anaesthetic Wound Infiltration in Bilateral Knee Arthroplasty: A Randomised, Placebo-Controlled, Doubleblind Trial. Acta Anaesthesiologica Scandinavica, 54, 543-548. https://doi.org/10.1111/j.1399-6576.2009.02196.x

[6] Fu, P., Wu, Y., Wu, H., Li, X., Qian, Q. and Zhu, Y. (2009) Efficacy of Intra-Articular Cocktail Analgesic Injection in Total Knee Arthroplasty-A Randomized Controlled Trial. Knee, 16, 280-284.

https://doi.org/10.1016/j.knee.2008.12.012

[7] Garcia, J.B., Barbosa Neto, J.O., Vasconcelos, J.W., Ferro, L.S. and Silva, R.C. (2010) Analgesic Efficacy of the Intra-Articular Administration of High Doses of Morphine in Patients Undergoing Total Knee Arthroplasty. Revista Brasileira de Anestesiologia, 60, 1-12.

[8] Dobrydnjov, I., Anderberg, C., Olsson, C., Shapurova, O., Angel, K. and Bergman, S. (2011) Intraarticular vs. Extraarticular Ropivacaine Infusion Following High-Dose Local Infiltration Analgesia after Total Knee Arthroplasty: A Randomized Doubleblind Study. Acta Orthopaedica, 82, 692-698.

https://doi.org/10.3109/17453674.2011.625535

[9] Chen, D.W., Hsieh, P.H., Huang, K.C., Hu, C.C., Chang, Y.H. and Lee, M.S. (2010) Continuous Intra-Articular Infusion of Bupivacaine for Post-Operative Pain Relief after Total Hip Arthroplasty: A Randomized, Placebo-Controlled, Double-Blind 
Study. European Journal of Pain, 14, 529-534.

https://doi.org/10.1016/j.ejpain.2009.08.008

[10] Koltka, K., Koknel-Talu, G., Asik, M. and Ozyalcin, S. (2011) Comparison of Efficacy of Intraarticular Application of Magnesium, Levolevobupivacaine and Lornoxicam with Placebo in Arthroscopic Surgery. Knee Surgery, Sports Traumatology, Arthroscopy, 19, 1884-1889. https://doi.org/10.1007/s00167-011-1497-x

[11] Senthilkumaran, S., Tate, R., Read, J.R. and Sutherland, A.G. (2010) Intra-Articular Morphine and Bupivacaine for Post-Operative Analgesia in Anterior Cruciate Ligament Reconstruction: A Prospective Randomised Controlled Trial. Knee Surgery, Sports Traumatology, Arthroscopy, 18, 731-735. https://doi.org/10.1007/s00167-009-0912-z

[12] Eroglu, A., Saracoglu, S., Erturk, E., Kosucu, M. and Kerimoglu, S. (2010) A Comparison of Intraarticular Morphine and Bupivacaine for Pain Control and Outpatient Status after an Arthroscopic Knee Surgery under a Low Dose of Spinal Anaesthesia. Knee Surgery, Sports Traumatology, Arthroscopy, 18, 1487-1495. https://doi.org/10.1007/s00167-010-1061-0

[13] Ayoglu, H., Altunkaya, H., Bayar, A., Turan, I.O., Ozer, Y. and Ege, A. (2010) The Effect of Intraarticular Combinations of Tramadol and Ropivacaine with Ketamine on Postoperative Pain after Arthroscopic Meniscectomy. Archives of Orthopaedic and Trauma Surgery, 130, 307-312. https://doi.org/10.1007/s00402-008-0770-Z

[14] Cekic, B., Geze, S., Erturk, E., Akdogan, A. and Eroglu, A. (2012) A Comparison of Levobupivacaine and Levobupivacaine-Tramadol Combination in Bilateral Infraorbital Nerve Block for Postoperative Analgesia after Nasal Surgery. Annals of Plastic Surgery.

[15] Gutierez-Mendoza, I., Peez-Correa, J.J., Serna-Vela, F., Góngora-Ortega, J., Vilchis-Huerta, V., Peez-Guzmán, C., et al. (2009) Analgesic Effect of Intra-Articular Fentanyl in Knee Arthroscopy to Treat Patellofemoral Lateral Hyperpressure Syndrome. Acta Ortop Mex, 23, 336-341.

[16] Liu, Y.C. and Wang, W.S. (2012) Human Mu-Opioid Receptor Gene A118G Polymorphism Predicts the Efficacy of Tramadol/Acetaminophen Combination Tablets (ultracet) in Oxaliplatin-Induced Painful Neuropathy. Cancer, 118, 1718-1725. https://doi.org/10.1002/cncr.26430 